\title{
Electrochemical Aziridination of Internal Alkenes with Primary Amines
}

\author{
Maksim Ošeka, ${ }^{\dagger}, \S$ Gabriele Laudadio, ${ }^{\dagger, \S}$ Nicolaas P. van Leest, ${ }^{\ddagger}$ Marco Dyga, ${ }^{\dagger}, \|$ Aloisio de A. \\ Bartolomeu, $\left.{ }^{\dagger}\right\urcorner$ L Lukas J. Gooßen,॥ Bas de Bruin, ${ }^{\ddagger}$ Kleber T. de Oliveira, ${ }^{7}$ Timothy Noël*,† \\ ${ }^{\dagger}$ Micro Flow Chemistry and Synthetic Methodology, Department of Chemical Engineering and Chemistry, Eindhoven Uni- \\ versity of Technology, Het Kranenveld, Bldg 14 - Helix, 5600 MB, Eindhoven, The Netherlands. \\ ‡ Homogeneous, Supramolecular and Bio-inspired Catalysis Group (HomKat), van 't Hoff Institute for Molecular Sci- \\ ences (HIMS), Universiteit van Amsterdam (UvA), Science Park 904, 1098 XH, Amsterdam, The Netherlands. \\ " Evonik Chair of Organic Chemistry, Fakultät für Chemie und Biochemie, Ruhr-Universität Bochum Universitätsstr. 150, \\ ZEMOS, 44801 Bochum, Germany. \\ 7 Departamento de Química, Universidade Federal de São Carlos, São Carlos, SP, 13565-905, Brazil.
}

\begin{abstract}
Aziridines are useful synthetic building blocks, widely employed for the preparation of various nitrogen-containing derivatives. As the current methods require the use of prefunctionalized amines, the development of a synthetic strategy towards aziridines, that can establishe the union of alkenes and amines, would be of great synthetic value. Herein, we report an electrochemical approach, which realizes this concept via an oxidative coupling between alkenes and primary alkyl amines. The reaction is carried out in an electrochemical flow reactor, leading to short reaction times ( $5 \mathrm{~min}$ ), high yields and broad scope. At the cathode, hydrogen is generated, which can be used in a second reactor to reduce the aziridine, yielding the corresponding hydroaminated product. Mechanistic investigations and DFT calculations revealed that the alkene is first anodically oxidized and subsequently reacted with the amine coupling partner.
\end{abstract}

Aziridines are a synthetically useful class of three-membered $\mathrm{N}$-containing saturated heterocycles, which play an essential role in the preparation of different nitrogen-containing derivatives. ${ }^{1}$ Despite their remarkable reactivity, imparted by the ringstrain $\left(28 \mathrm{kcal} \mathrm{mol}^{-1}\right)$, aziridines are also present in many pharmacologically active natural products, such as antibiotics and anticancer agents. ${ }^{2}$ Consequently, the development of new methods to prepare aziridine structural motifs remains a contemporary subject of interest to synthetic organic chemists. Promising results have been obtained for the synthesis of both racemic and enantiomerically-enriched aziridines, ${ }^{3}$ which can be essentially categorized in three main categories: i) addition of a nitrogen-containing moiety to an alkene, ii) addition of substituted carbenes to a $\mathrm{C}=\mathrm{N}$ bond, and iii) cyclization of 2haloamines or 2-aminoalcohols. ${ }^{\text {la }}$ Amongst these different approaches, ${ }^{4}$ the addition of a nitrogen-containing reagent to an alkene is the most popular due its efficiency and versatility. ${ }^{5}$ However, most of these methodologies require the use of a transition metal catalyst, such as copper, ${ }^{6}$ rhodium, ${ }^{7}$ gold,${ }^{8}$ cobalt, ${ }^{9}$ iron ${ }^{10}$ or palladium, ${ }^{11}$ in combination with a suitable and activated nitrene precursor, such as iminoiodinanes and organic azides (Figure 1A). ${ }^{12}$

In order to foster more sustainable and transition-metal free alternatives, new strategies to access aziridines have been devised using electrochemical activation (Figure 1B). ${ }^{13}$ Yudin and coworkers developed an electrochemical aziridination, which uses $\mathrm{N}$-amino-phthalimide as the source of electrophilic nitrogen. ${ }^{2 \mathrm{~b}, 14}$ An iodide-mediated electrocatalytic variant of this protocol was realized by Little, Zheng, and coworkers. ${ }^{15}$ Recently, Cheng et al. established an electrochemical strategy, which utilizes a trifluoromethylated sulfamate as coupling partner. ${ }^{16}$

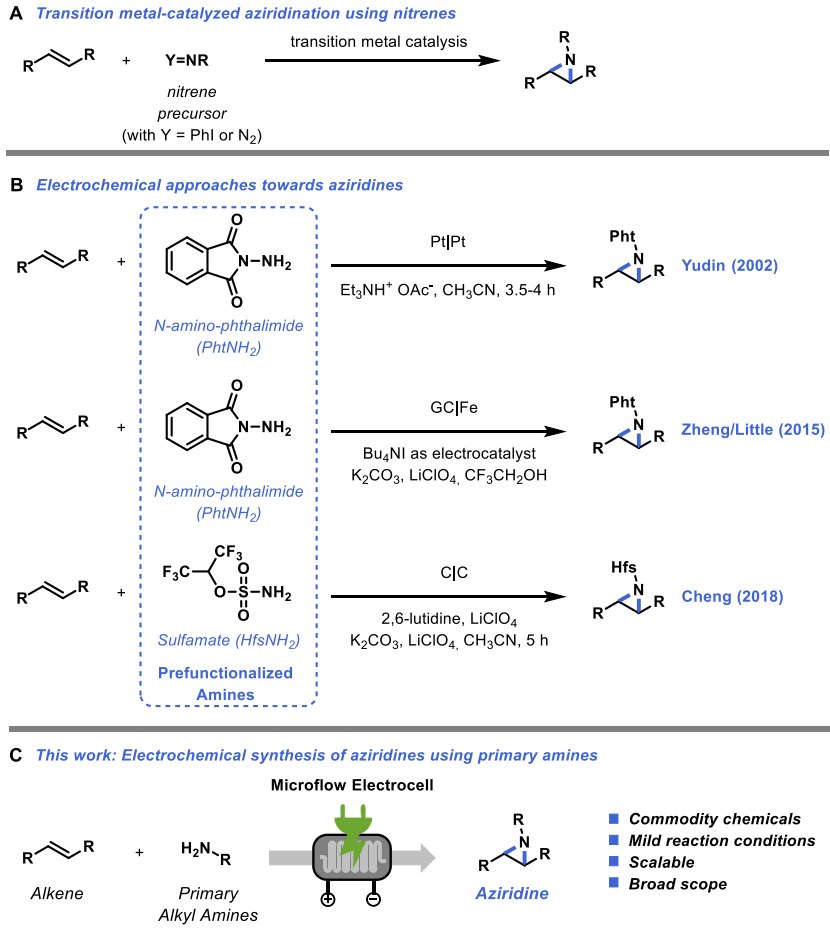

Figure 1. Development of an electrochemical synthesis of aziridines starting from alkenes and primary alkyl amines. (A) Transition metal-catalyzed aziridination of alkenes with nitrene precursors. (B) Established synthetic routes for the synthesis of aziridines using electrochemistry. (C) Electrochemical synthesis of aziridines using primary alkyl amines as aminating reagents. 
Despite the synthetic value of these electrochemical and other approaches towards aziridines, the scope of the nitrogen-containing coupling partners remains restricted to a limited set of prefunctionalized amines, either $\mathrm{PhtNH}_{2}$ or $\mathrm{HfsNH}_{2}$ (Figure 1B). It is, however, manifest that an electrochemical coupling between olefins and amines would be of significant value given the broad availability and the low cost of these building blocks (Figure 1C). Such a strategy would also remove the requirement for substrate prefunctionalization, thereby increasing the atom efficiency of the transformation while expanding the scope of available molecular fragments. Based on recent work from our lab involving the electrochemical synthesis of sulfonamides ${ }^{17}$ and sulfonyl fluorides, ${ }^{18}$ we surmised that direct electrochemical activation of either olefins or amines via anodic oxidation might enable the expedient formation of a carbon-nitrogen bond, eventually leading to the targeted aziridines. Herein, we report on our efforts to develop such an approach, enabling for the first time the union of olefins and amines, as convenient and widely available starting materials, to prepare aziridines.

Our investigation into this new aziridination protocol began with the introduction of trans-anethole and cyclohexylamine into an electrochemical microflow reactor with a small interelectrode gap $(250 \mu \mathrm{m})$ between the carbon anode and stainless steel cathode (Table 1). ${ }^{19}$ After an extensive optimization of the different reaction variables (See Supporting Information), a good isolated yield ( $72 \%$ yield) could be obtained in only 5 minutes of residence time under galvanostatic conditions using an excess of amine (5 equiv.) in $\mathrm{CH}_{3} \mathrm{CN}$ (Table 1, Entry 1). Addition of 5 equivalents of hexafluoroisopropanol (HFIP) proved beneficial for the targeted transformation and serves as a radical-stabilizing co-solvent and as a proton source for the cathodic half-reaction, generating hydrogen as a useful byproduct (Table 1, Entries 1 and 2).$^{20}$ Reducing the amount of amine resulted in lower yields (Table 1, Entry 3). Interestingly, the presence of a substoichiometric amount of $\gamma$-terpinene proved beneficial to prevent overoxidation of the starting material (Table 1, Entry 4). Other electrode combinations did not lead to improved results or were less effective for different substrate combinations (Table 1, Entry 5; see also Table S6). HFIP was the optimal proton source for the electrochemical aziridination, while other acids proved less effective (Table 1, Entry 6; see also Table S4). As expected, the reaction was electrochemical in nature as no conversion was observed in the absence of electricity (Table 1, Entry 7). Finally, the reaction was less effective in a batch reactor, requiring longer reaction times which resulted in an increased generation of byproducts (Table 1, Entry 8). ${ }^{21}$

Having established optimal reaction conditions, we next investigated the generality of this electrochemical aziridination reaction. As shown in Figure 2, a wide variety of structurally and electronically diverse primary alkyl amines and alkenes can be readily engaged in this transformation. In most cases, the targeted aziridines could be isolated as pure compounds (product A) in good isolated yields, while other compounds proved to be too fragile to be isolated via standard work-up and chromatographic procedures. We opted to isolate those compounds after subsequent ring opening with a suitable nucleophile, i.e. 4-bro- mothiophenol, as the corresponding 1,2-amino thioether (product B) ${ }^{22}$ Interestingly, unprotected $\mathrm{N}-\mathrm{H}$ aziridines ( $\mathbf{1}$ and $\mathbf{2 8}$ ) can be prepared by using ammonia in either water $(40 \% \mathrm{w} / \mathrm{w})$ or methanol $(7 \mathrm{M})$. It should be noted that these $\mathrm{N}-\mathrm{H}$ aziridines are extremely challenging to make and only recently a method towards these compounds using rhodium catalysis and $O-(2,4-$ dinitrophenyl)hydroxylamine, as an electrophilic nitrogen reagent, was reported. ${ }^{7}$ Furthermore, a variety of primary amines are competent coupling partners in this electrochemical aziridination protocol, including methylamine (2), butylamine (3), isopropylamine (4), tert-butylamine (5), cyclopropanemethylamine (6), cyclobutylamine (7), cyclopentylamine (8) and cyclohexylamine (9), furnishing the targeted products in good isolated yields. The use of a narrow-gap flow cell allows us to readily scale the reaction conditions without the need for reoptimization; $;^{21,23}$ by pumping the reagents continuously into the reactor for a prolonged amount of time, compound $\mathbf{9}$ was isolated on a $10 \mathrm{mmol}$ scale. Also activated amines, such as propargylamine (10), benzylamine (11-12) and $\alpha$-methylbenzylamine (13) are effective in this transformation. Finally, the esters of amino acids glycine (14) and phenylalanine (15) can be readily engaged in this aziridination protocol, providing opportunities for peptide modification. Notably, no racemization of the chiral center occurs under the electrochemical reaction conditions.

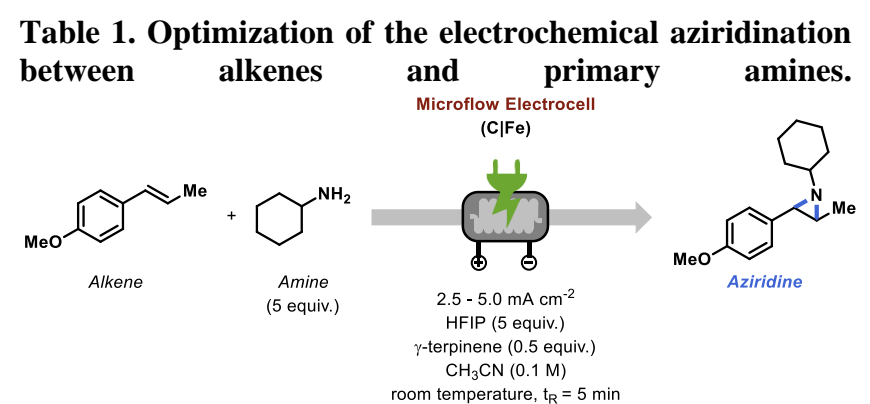

\begin{tabular}{ccc} 
Entry & Variation from the standard conditions & Yield $(\%)^{b}$ \\
\hline $\mathbf{1}^{\mathbf{a}}$ & none & $\mathbf{8 8}(\mathbf{7 2})^{\mathrm{c}}$ \\
2 & neat HFIP & traces \\
3 & 2.5 equiv. amine & 75 \\
4 & no $\gamma$-terpinene & 78 \\
5 & graphite cathode & 59 \\
6 & $p-T s O H(1$ equiv.) & 32 \\
7 & no electricity & 0 \\
8 & batch ( $\left.\mathrm{t}_{\mathrm{R}}=16 \mathrm{~h}\right)$ & $14^{d}$
\end{tabular}

${ }^{a}$ Reaction Conditions: anethole $(2 \mathrm{mmol}), \gamma$-terpinene ( 0.5 equiv.), cyclohexylamine (5 equiv.), HFIP (5 equiv.), $\mathrm{CH}_{3} \mathrm{CN}(0.1 \mathrm{M}), \mathrm{C}$ anode/Fe cathode, $2.5-5 \mathrm{~mA} \mathrm{~cm}{ }^{-2} .{ }^{b}$ Yield determined by GC-FID with biphenyl as internal standard. ${ }^{c}$ Isolated yield. ${ }^{d}$ Batch reaction conditions: Electrasyn, $3.1 \mathrm{~mA} \mathrm{~cm}{ }^{-2}, 3.5 \mathrm{~F}, \mathrm{C}$ anode/Fe cathode, $0.5 \mathrm{mmol}$ scale.

Similarly, we investigated the variability of the alkene reaction partner that is compatible with the reaction conditions. Both electro-neutral and electron-rich internal alkenes can be effectively reacted with cyclohexylamine. For instance, $(E)-1-$ methoxy-2-(prop-1-en-1-yl)benzene (16) and (E)-1,2-dimethoxy-4-(prop-1-enyl)benzene (17) delivered the desired functionalized product in good yield. When the substrate contained two double bonds, the 

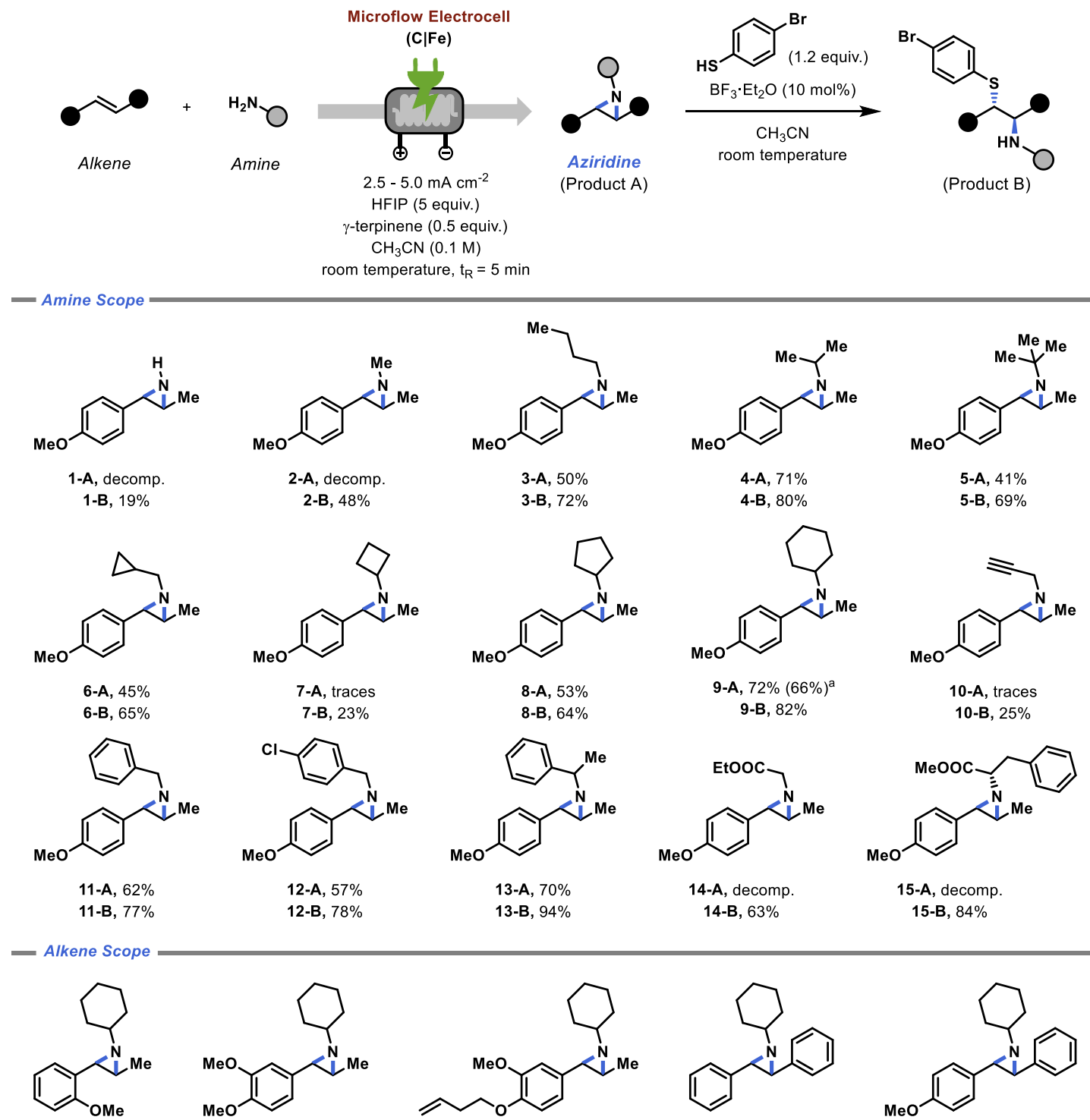

16-A, $58 \%$

17-A, decomp. 17-B, $72 \%$
18-A, decomp. 18-B, $72 \%$

19-A, $25 \%,(26 \%)^{\text {b }}$

20-A, $59 \%$<smiles>O=S(=O)(Oc1ccc(CN(Cc2ccccc2)C2CCCCC2)cc1)N1CCCCC1</smiles>

21-A, $29 \%$

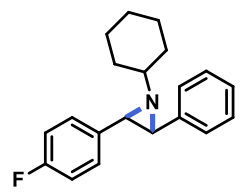

22-A, 33\%

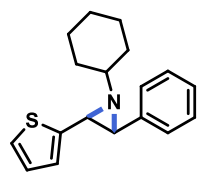

23-A, $30 \%$

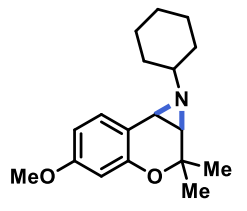

24-A, $93 \%$<smiles>COc1ccc(C2C(N3CCCCC3)C2(C)C)cc1</smiles>

25-A, $78 \%$<smiles>c1ccc(C2(c3ccccc3)c3ccccc3C(c3ccccc3)(c3ccccc3)N2C2CCCCC2)cc1</smiles><smiles>c1ccc(CN(C2CCCCC2)C(c2ccccc2)c2ccccc2-c2ccccc2)cc1</smiles>

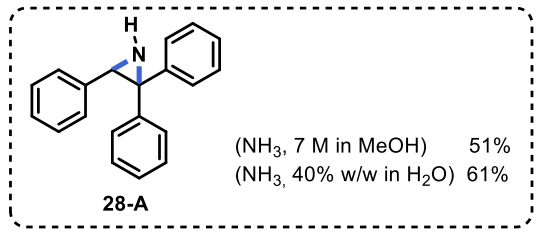

Figure 2. Substrate scope for the electrochemical aziridine synthesis. Reaction Conditions A: alkene (1 mmol), amine (5 equiv.), HFIP (5 equiv.), $\gamma$-terpinene ( 0.5 equiv.), $\mathrm{CH}_{3} \mathrm{CN}(0.1 \mathrm{M}), \mathrm{C}$ anode/Fe cathode, $2.5-5 \mathrm{~mA} \mathrm{~cm}^{-2}$. Decomposition refers to instability of the product, making isolation of the compound impossible. Reaction Conditions $\mathbf{B}$ : isolated yields refer to the ring-opened product. The nucleophilic quenching was carried out in the collection vial with 4-bromothiophenol (1.2 equiv.) in the presence of $\mathrm{BF}_{3} . \mathrm{OEt}_{2}(10 \mathrm{~mol} \%)$. ${ }^{\mathrm{a}} 10 \mathrm{mmol}$ scale reaction. ${ }^{\mathrm{b}}$ cis-Stilbene used as a substrate. 
terminal double bond remained intact providing exclusively the internal trans-aziridine (18). This site specificity may be exploited for the selective aziridination of other poly-ene compounds. Next, a variety of stilbenes (19-22) was subjected to the reaction conditions, highlighting the breadth of our transformation in comparison to previous electrochemical aziridination strategies. Both cis- and trans-stilbene led to the same transaziridine (19-A). In addition, heterocyclic moieties like thiophene (23-A) are compatible with the electrochemical conditions, yielding synthetically useful quantities of the targeted aziridine. The cyclic alkene of precocene I (24-A), a natural chromene, was found to be an adequate reaction partner and furnished the targeted product in excellent yield. Next, we moved our attention to the functionalization of trisubstituted alkenes. Even for such sterically congested double bonds, the targeted product can be obtained in good to excellent yields for both electron-rich (25-A) and electron-neutral (26-A) alkenes. Notably, a spirocyclic aziridine (27-A) could be accessed as well using this electrochemical aziridination strategy.

All single electron transfer events relevant for the electrochemical aziridination occur at the anode, while the other halfreaction generates hydrogen as a useful yet hazardous byproduct at the cathode. We wondered if this hydrogen could be productively used in a follow-up hydrogenation step to form the corresponding hydroaminated product (Figure 3 ). Indeed, by connecting a packed-bed reactor filled with $\mathrm{Pd} / \mathrm{C}$ to the electrochemical flow reactor, the gas-liquid flow exiting the first reactor can be directed over the $\mathrm{Pd} / \mathrm{C}$ bed without intermediate isolation. To our delight, the corresponding hydroaminated product (9C) could be promptly obtained in good overall yield. ${ }^{24}$ Furthermore, we observed a single phase exiting the packedbed reactor indicating that nearly all hydrogen gas was consumed. In contrast, when this experiment was conducted in batch, additional hydrogen to compensate for leakage to the headspace was required to obtain full conversion, albeit at a lower isolated yield. It should be further noted that this paired reaction sequence in flow not only increases the yield and the atom efficiency of the process, but also allows for facile reuse and recycling of the $\mathrm{Pd} / \mathrm{C}$ bed and it reduces the risks associated with the handling of combustible hydrogen gas due its immediate consumption in a follow-up reaction. ${ }^{21,25}$

To obtain insights into the underlying mechanism, we performed additional experiments and studied possible mechanistic pathways by means of density functional theory (DFT) calculations (Figure 4). Cyclic voltammetry (CV) experiments revealed two subsequent oxidations of the alkene moiety (Figure 4A). The first oxidation results in the formation of a radical cation, while the second oxidation leads to oxidative cleavage of the olefin. Small quantities of the corresponding Schiff base could be found in the reaction mixture confirming this hypothesis (Figure 4B). ${ }^{26} \mathrm{We}$ anticipated that this overoxidation could be countered by adding a suitable donor of hydrogens and electrons. Indeed, 0.5 equivalents 1,4-cyclohexadiene (1,4-CHD) allowed to reduce the amount of imine significantly. Also, $\gamma$ terpinene, which is a more stable, non-toxic and cheaper alternative for 1,4-CHD, enabled the suppression of the overoxidation of the alkene as shown in the CV (Figure 4A). ${ }^{27}$ While our experimental results indicate that oxidation of the alkene is most likely the first step, CV analysis showed that a competitive activation of cyclohexylamine could occur as well (See Supporting Information). However, due to the irreversible nature of the oxidation of both reaction partners and the similar set-off potentials, it is difficult to predict the first anodic event in this aziridination protocol. Hence, we decided to obtain further insights via DFT calculations. These computational studies revealed that the anodic oxidation of anethole is indeed the first step in the electrochemical aziridination $\left(\Delta G^{\mathrm{o}}{ }_{298 \mathrm{~K}}=+28.3 \mathrm{kcal} \mathrm{mol}^{-1}\right.$ and $+1.226 \mathrm{~V}$ vs SCE) (Figure 4D). An alternative pathway starting from the oxidation of the amine coupling partner, yielding the aminium radical, is energetically disfavored due to the higher required energy input $\left(\Delta G^{\mathrm{o}}{ }_{298 \mathrm{~K}}=+38.4 \mathrm{kcal} \mathrm{mol}^{-1}\right.$ and $+1.665 \mathrm{~V}$ vs SCE) (see Supporting Information). However, we cannot exclude that for some substrate combinations, the reaction can be initiated via the formation of the aminium radical. Once the radical cation of anethole is formed, it readily reacts with an amine coupling partner yielding intermediate $\mathbf{C}$ (Figure 4D) via a low-barrier transition state. After deprotonation and subsequent single electron transfer, a carbocation $(\mathbf{E})$ is formed which can undergo a rapid barrier-less intramolecular ring closure and deprotonation to yield the target aziridine $(\mathbf{F}){ }^{28}$ The reaction is exergonic after the initial oxidation $\left(\Delta G^{\mathrm{o}}{ }_{298 \mathrm{~K}}=-11.7\right.$ $\mathrm{kcal} \mathrm{mol}^{-1}$ ) but endergonic with respect to the starting materials, consistent with the required energy input in the form of electrons during the reaction.

The electrochemical approach reported herein demonstrates the possibility to convert directly olefins and primary alkyl amines into synthetically useful aziridines. We expect that the operational simplicity of this protocol and its potential to use common and broadly available starting materials will find widespread use among organic chemistry practitioners both in academia and industry.

\section{ASSOCIATED CONTENT}

\section{Supporting Information}

Experimental procedures, reaction optimization, mechanistic data, analytical data $\left({ }^{1} \mathrm{H},{ }^{19} \mathrm{~F}\right.$ and ${ }^{13} \mathrm{C}$ NMR, HRMS $)$ and details of the computational study.

\section{AUTHOR INFORMATION}

\section{Corresponding Author}

*.Noel@tue.nl

\section{Author Contributions}

$\S$ These authors contributed equally to this work.

\section{Notes}

The authors declare no competing financial interests.

\section{ACKNOWLEDGMENT}

We acknowledge financial support from the Dutch Science Foundation (NWO) for a VIDI grant for T.N. (SensPhotoFlow, No. 14150) and the Estonian Research Council (ETAG) for a PUT postdoctoral grant for M.O. (PUTJD821). A.A.B. and K.T.O. thank the São Paulo Research Foundation for a FAPESP Fellowship Grant (2018/08772-6). The Deutsche Forschungsgemeinschaft (DFG, German Research Foundation) under Germany's Excellence Strategy - EXC 2033 - 390677874 - RESOLV, is kindly acknowledged for funding the research of M.D. and L.J.G. Finally, we also would like to thank Ing. Jan Goeman (Ghent University) for recording the HRMS and M. Kimm and D. Trubitsõn (Tallinn University of Technology) for chiral HPLC analysis. 


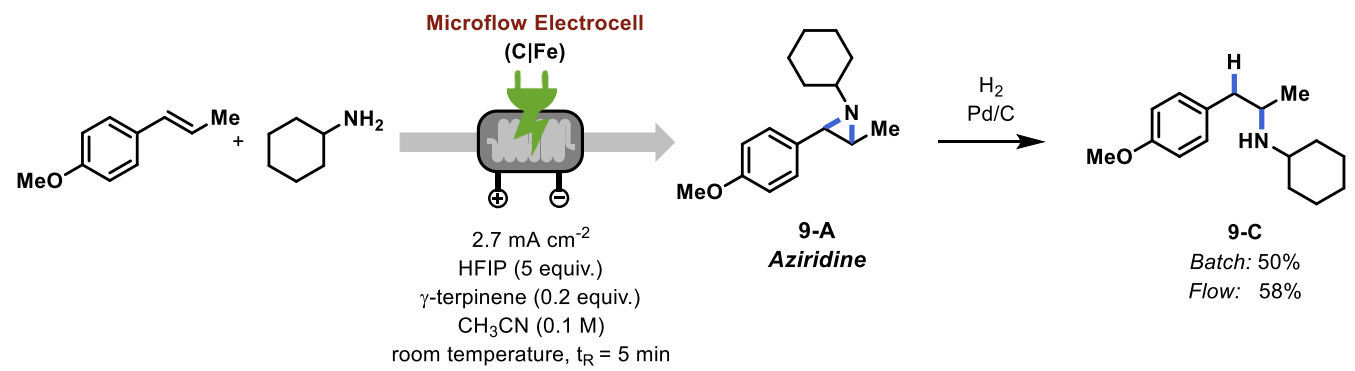

Figure 3. Two-step hydroamination protocol by combining the electrochemical aziridine synthesis and a subsequent hydrogenation. Reaction Conditions C: alkene ( $1 \mathrm{mmol}$ ), amine (5 equiv.), HFIP (5 equiv.), $\gamma$-terpinene ( 0.2 equiv.), $\mathrm{CH}_{3} \mathrm{CN}(0.1 \mathrm{M}), \mathrm{C}$ anode/Fe cathode, $2.7 \mathrm{~mA}$ $\mathrm{cm}^{-2}$. Batch conditions: $\mathrm{Pd} / \mathrm{C}(5 \mathrm{~mol} \%), \mathrm{H}_{2}$ (1 bar). Flow conditions: $\mathrm{Pd} / \mathrm{C}$ (150 mg cartridge).
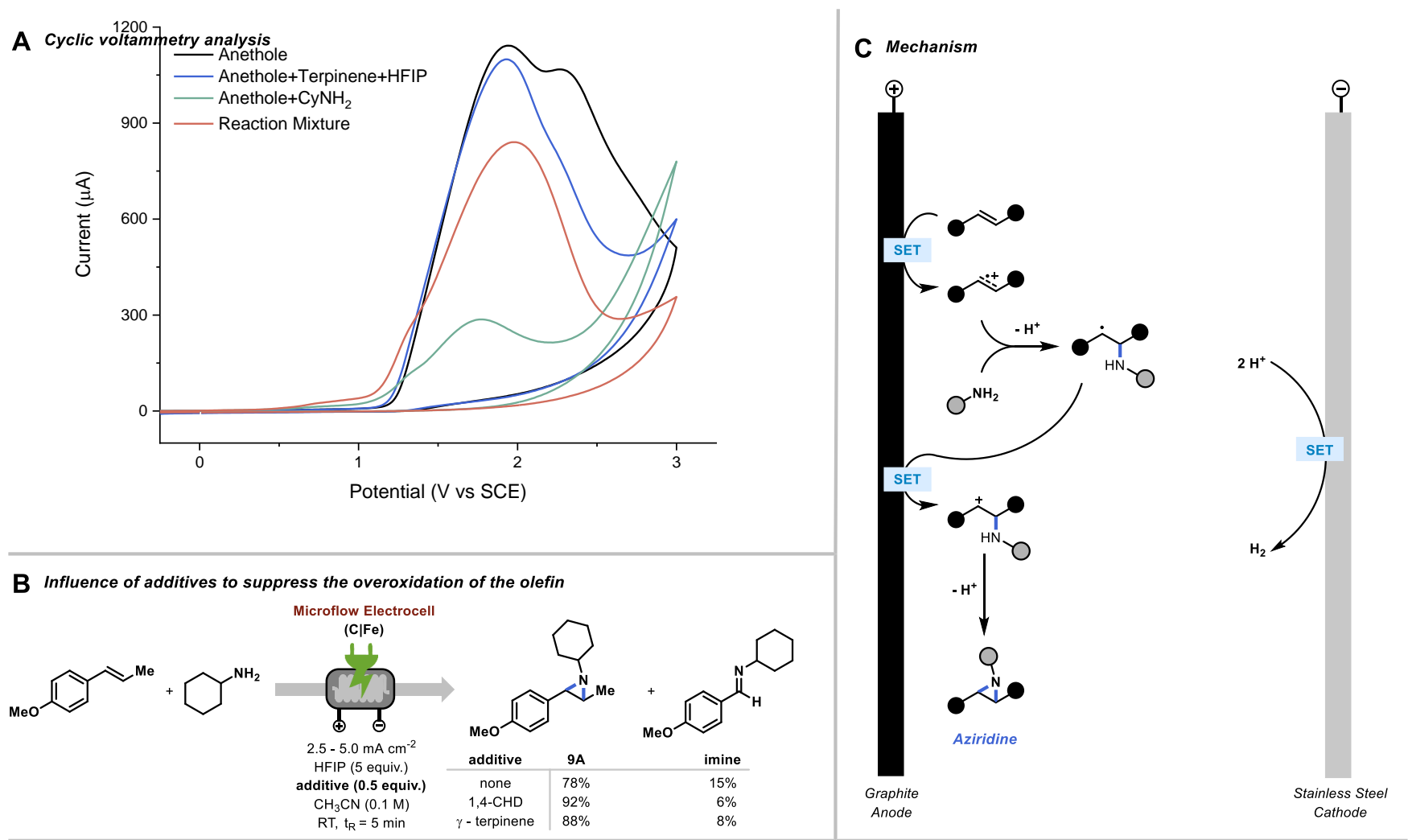

\section{DFT Calculation}

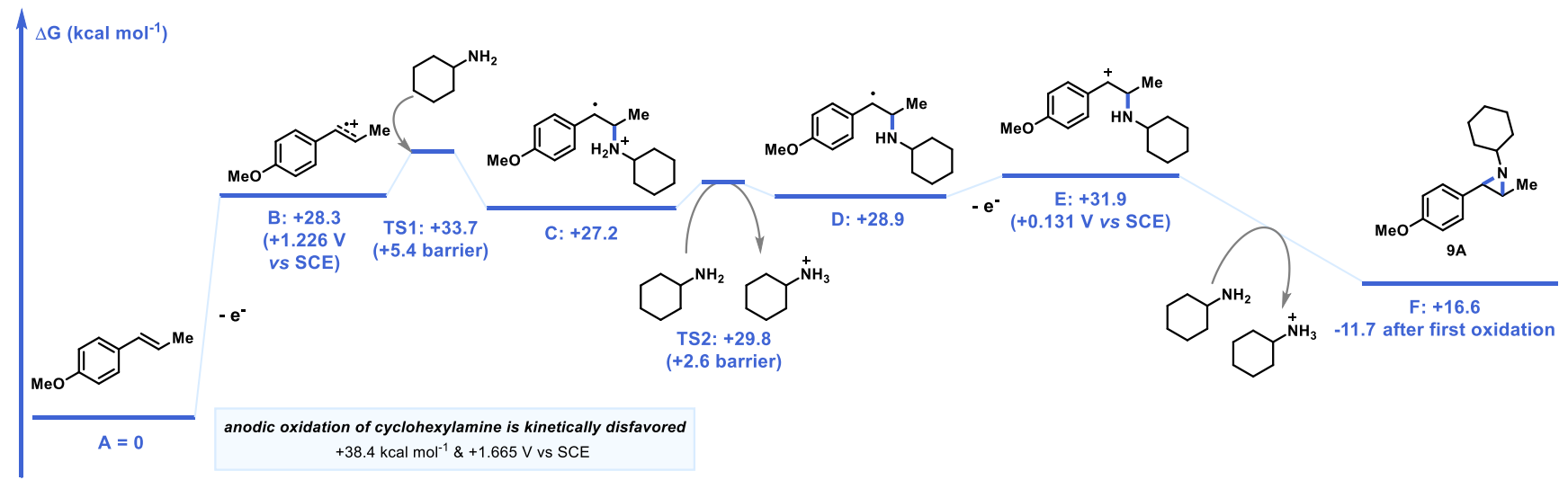

Figure 4. Mechanistic investigation. (A) Cyclic voltammetry experiments. (B) Addition of a reducing agent to suppress overoxidation of the alkene. (C) Proposed mechanism. (D) DFT Gibbs free energy profile at $298 \mathrm{~K}$ (in kcal mol-1). Calculations were performed at the B3LYP/def2-TZVP//B3LYP/def2-TZVP(COSMO) level of theory on an $\mathrm{m} 4$ grid with disp3 dispersion corrections. 


\section{REFERENCES}

1. (a) Singh, G. S., Advances in synthesis and chemistry of aziridines. In Adv. Heterocycl. Chem., Scriven, E. F. V.; Ramsden, C. A., Eds. Academic Press: 2019; Vol. 129, pp 245-335; (b) Campeau, L.-C.; Hazari, N., Cross-Coupling and Related Reactions: Connecting Past Success to the Development of New Reactions for the Future. Organometallics 2019, 38 (1), 3-35; (c) Sabir, S.; Kumar, G.; Verma, V. P.; Jat, J. L., Aziridine Ring Opening: An Overview of Sustainable Methods. ChemistrySelect 2018, 3 (13), 3702-3711; (d) Sabir, S.; Kumar, G.; Jat, J. L., Unprotected Aziridines: A Synthetic Overview. Asian Journal of Organic Chemistry 2017, 6 (7), 782-793; (e) Callebaut, G.; Meiresonne, T.; De Kimpe, N.; Mangelinckx, S., Synthesis and Reactivity of 2-(Carboxymethyl)aziridine Derivatives. Chem. Rev. 2014, 114 (16), 7954-8015; (f) Singh, G. S.; D'Hooghe, M.; De Kimpe, N., Synthesis and Reactivity of C-Heteroatom-Substituted Aziridines. Chem. Rev. 2007, 107 (5), 2080-2135; (g) Yudin, A. K., Aziridines and epoxides in organic synthesis. Wiley-VCH: Weinheim: 2006.

2. (a) Singh, G. S., Synthetic Aziridines in Medicinal Chemistry: A Mini-Review. Mini-Reviews in Medicinal Chemistry 2016, 16 (11), 892-904; (b) Watson, I. D. G.; Yu, L.; Yudin, A. K., Advances in Nitrogen Transfer Reactions Involving Aziridines. Acc. Chem. Res. 2006, 39 (3), 194-206.

3. (a) Roma, E.; Tosi, E.; Miceli, M.; Gasperi, T., Asymmetric Organocatalytic Aziridination: Recent Advances. Asian Journal of Organic Chemistry 2018, 7 (12), 2357-2367; (b) Degennaro, L.; Trinchera, P.; Luisi, R., Recent Advances in the Stereoselective Synthesis of Aziridines. Chem. Rev. 2014, 114 (16), 7881-7929.

4. (a) Zakrzewski, J.; Smalley, A. P.; Kabeshov, M. A.; Gaunt, M. J.; Lapkin, A. A., Continuous-Flow Synthesis and Derivatization of Aziridines through Palladium-Catalyzed C (sp3)- H Activation. Angew. Chem. Int. Ed. 2016, 55 (31), 8878-8883; (b) McNally, A.; Haffemayer, B.; Collins, B. S. L.; Gaunt, M. J., Palladium-catalysed $\mathrm{C}-\mathrm{H}$ activation of aliphatic amines to give strained nitrogen heterocycles. Nature 2014, 510 (7503), 129-133; (c) Rios, R.; Córdova, A., $\mathrm{C}-\mathrm{N}$ Bond Formation: Aziridine Formation. In Comprehensive Chirality, Carreira, E. M.; Yamamoto, H., Eds. Elsevier: Amsterdam, 2012; pp 399-413.

5. (a) Yu, Y.; Li, M.; Zhang, Y.; Liu, Y.; Shi, L.; Wang, W.; $\mathrm{Li}, \quad \mathrm{H}$, Construction of N-Alkyl- and N-Arylaziridines from Unprotected Amines via C-H Oxidative Amination Strategy. Org. Lett. 2019, 21 (4), 904-907; (b) Yu, W.-L.; Chen, J.-Q.; Wei, Y.-L.; Wang, Z.-Y.; Xu, P.-F., Alkene functionalization for the stereospecific synthesis of substituted aziridines by visible-light photoredox catalysis. Chem. Commun. 2018, 54 (16), 1948-1951; (c) Wang, H.; Yang, J. C.; Buchwald, S. L., CuH-Catalyzed Regioselective Intramolecular Hydroamination for the Synthesis of Alkyl-Substituted Chiral Aziridines. J. Am. Chem. Soc. 2017, 139 (25), 8428-8431.

6. For a selection of $\mathrm{Cu}$-catalyzed aziridinations, see: (a) Jung, N.; Bräse, S., New Catalysts for the Transition-Metal-Catalyzed Synthesis of Aziridines. Angew. Chem. Int. Ed. 2012, 51 (23), 55385540; (b) Lebel, H.; Parmentier, M., Copper-catalyzed enantioselective aziridination of styrenes. Pure Appl. Chem. 2010, 82 (9), 1827-1833; (c) Lebel, H.; Lectard, S.; Parmentier, M., Copper-Catalyzed Alkene Aziridination with N-Tosyloxycarbamates. Org. Lett. 2007, 9 (23), 4797-4800; (d) Evans, D. A.; Bilodeau, M. T.; Faul, M. M., Development of the Copper-Catalyzed Olefin Aziridination Reaction. J. Am. Chem. Soc. 1994, 116 (7), 2742-2753.

7. Jat, J. L.; Paudyal, M. P.; Gao, H.; Xu, Q.-L.; Yousufuddin, M.; Devarajan, D.; Ess, D. H.; Kürti, L.; Falck, J. R., Direct stereospecific synthesis of unprotected N-H and N-Me aziridines from olefins. Science 2014, 343 (6166), 61-65.

8. Li, Z.; Ding, X.; He, C., Nitrene Transfer Reactions Catalyzed by Gold Complexes. J. Org. Chem. 2006, 71 (16), 58765880 .

9. (a) van Leest, N. P.; Tepaske, M. A.; Oudsen, J.-P. H.; Venderbosch, B.; Rietdijk, N. R.; Siegler, M. A.; Tromp, M.; van der Vlugt, J. I.; de Bruin, B., Ligand Redox Noninnocence in [CoIII(TAML)]0/- Complexes Affects Nitrene Formation. J. Am.
Chem. Soc. 2020, 142 (1), 552-563; (b) Goswami, M.; Lyaskovskyy, V.; Domingos, S. R.; Buma, W. J.; Woutersen, S.; Troeppner, O.; Ivanović-Burmazović, I.; Lu, H.; Cui, X.; Zhang, X. P.; Reijerse, E. J.; DeBeer, S.; van Schooneveld, M. M.; Pfaff, F. F.; Ray, K.; de Bruin, B., Characterization of Porphyrin-Co(III)-'Nitrene Radical' Species Relevant in Catalytic Nitrene Transfer Reactions. J. Am. Chem. Soc. 2015, 137 (16), 5468-5479; (c) Jin, L.-M.; Xu, X.; Lu, H.; Cui, X.; Wojtas, L.; Zhang, X. P., Effective Synthesis of Chiral N-Fluoroaryl Aziridines through Enantioselective Aziridination of Alkenes with Fluoroaryl Azides. Angew. Chem. Int. Ed. 2013, 52 (20), 5309-5313; (d) Olivos Suarez, A. I.; Jiang, H.; Zhang, X. P.; de Bruin, B., The radical mechanism of cobalt(ii) porphyrin-catalyzed olefin aziridination and the importance of cooperative H-bonding. Dalton Trans. 2011, 40 (21), 5697-5705.

10. Liang, L.; Lv, H.; Yu, Y.; Wang, P.; Zhang, J.-L., Iron(iii) tetrakis(pentafluorophenyl)porpholactone catalyzes nitrogen atom transfer to $\mathrm{C}=\mathrm{C}$ and $\mathrm{C}-\mathrm{H}$ bonds with organic azides. Dalton Trans. 2012, 41 (5), 1457-1460.

11. Ohno, H.; Toda, A.; Miwa, Y.; Taga, T.; Osawa, E.; Yamaoka, Y.; Fujii, N.; Ibuka, T., First Palladium-Catalyzed Aziridination Reaction of Amino Allenes. J. Org. Chem. 1999, 64 (9), 2992-2993.

12. (a) Darses, B.; Rodrigues, R.; Neuville, L.; Mazurais, M.; Dauban, P., Transition metal-catalyzed iodine(iii)-mediated nitrene transfer reactions: efficient tools for challenging syntheses. Chem. Commun. 2017, 53 (3), 493-508; (b) Fantauzzi, S.; Caselli, A.; Gallo, E., Nitrene transfer reactions mediated by metallo-porphyrin complexes. Dalton Trans. 2009, (28), 5434-5443.

13. For some selected reviews on electrochemical activation of organic molecules, see: (a) Kingston, C.; Palkowitz, M. D.; Takahira, Y.; Vantourout, J. C.; Peters, B. K.; Kawamata, Y.; Baran, P. S., A Survival Guide for the "Electro-curious". Acc. Chem. Res. 2020, 53 (1), 72-83; (b) Ghosh, M.; Shinde, V. S.; Rueping, M., A review of asymmetric synthetic organic electrochemistry and electrocatalysis: concepts, applications, recent developments and future directions. Beilstein J. Org. Chem. 2019, 15, 2710-2746; (c) Möhle, S.; Zirbes, M.; Rodrigo, E.; Gieshoff, T.; Wiebe, A.; Waldvogel, S. R., Modern Electrochemical Aspects for the Synthesis of Value-Added Organic Products. Angew. Chem. Int. Ed. 2018, 57 (21), 6018-6041; (d) Yan, M.; Kawamata, Y.; Baran, P. S., Synthetic Organic Electrochemical Methods Since 2000: On the Verge of a Renaissance. Chem. Rev. 2017, 117 (21), 13230-13319.

14. (a) Siu, T.; Picard, C. J.; Yudin, A. K., Development of Electrochemical Processes for Nitrene Generation and Transfer. J. Org. Chem. 2005, 70 (3), 932-937; (b) Siu, T.; Yudin, A. K., Practical olefin aziridination with a broad substrate scope. J. Am. Chem. Soc. 2002, 124 (4), 530-531.

15. Chen, J.; Yan, W.-Q.; Lam, C. M.; Zeng, C.-C.; Hu, L.-M.; Little, R. D., Electrocatalytic aziridination of alkenes mediated by nBu4NI: a radical pathway. Org. Lett. 2015, 17 (4), 986-989.

16. Li, J.; Huang, W.; Chen, J.; He, L.; Cheng, X.; Li, G., Electrochemical aziridination by alkene activation using a sulfamate as the nitrogen source. Angew. Chem. Int. Ed. 2018, 57 (20), 5695-5698.

17. Laudadio, G.; Barmpoutsis, E.; Schotten, C.; Struik, L.; Govaerts, S.; Browne, D. L.; Noël, T., Sulfonamide Synthesis through Electrochemical Oxidative Coupling of Amines and Thiols. J. Am. Chem. Soc. 2019, 141 (14), 5664-5668.

18. (a) Cao, Y.; Adriaenssens, B.; Bartolomeu, A. A.; Laudadio, G.; de Oliveira, K. T.; Noël, T., Accelerating sulfonyl fluoride synthesis through electrochemical oxidative coupling of thiols and potassium fluoride in flow. J. Flow Chem. 2020, 10 (1), 191-197; (b) Laudadio, G.; Bartolomeu, A. A.; Verwijlen, L. M. H. M.; Cao, Y.; de Oliveira, K. T.; Noël, T., Sulfonyl Fluoride Synthesis through Electrochemical Oxidative Coupling of Thiols and Potassium Fluoride. J. Am. Chem. Soc. 2019, 141 (30), 11832-11836.

19. Laudadio, G.; De Smet, W.; Struik, L.; Cao, Y.; Noël, T., Design and application of a modular and scalable electrochemical flow microreactor. J. Flow Chem. 2018, 8, 157-165.

20. (a) Schulz, L.; Waldvogel, S. R., Solvent Control in ElectroOrganic Synthesis. Synlett 2019, 30 (03), 275-286; (b) Colomer, I.; Chamberlain, A. E. R.; Haughey, M. B.; Donohoe, T. J., 
Hexafluoroisopropanol as a highly versatile solvent. Nat. Rev. Chem. 2017, 1 (11), 0088; (c) Berkessel, A.; Adrio, J. A.; Hüttenhain, D.; Neudörfl, J. M., Unveiling the "Booster Effect" of Fluorinated Alcohol Solvents: Aggregation-Induced Conformational Changes and Cooperatively Enhanced H-Bonding. J. Am. Chem. Soc. 2006, 128 (26), 8421-8426.

21. Noël, T.; Cao, Y.; Laudadio, G., The Fundamentals Behind the Use of Flow Reactors in Electrochemistry. Acc. Chem. Res. 2019, 52 (10), 2858-2869.

22. Stanković, S.; D'Hooghe, M.; Catak, S.; Eum, H.; Waroquier, M.; Van Speybroeck, V.; De Kimpe, N.; Ha, H.-J., Regioselectivity in the ring opening of non-activated aziridines. Chem. Soc. Rev. 2012, 41 (2), 643-665.

23. (a) Elsherbini, M.; Wirth, T., Electroorganic Synthesis under Flow Conditions. Acc. Chem. Res. 2019, 52 (12), 3287-3296; (b) Pletcher, D.; Green, R. A.; Brown, R. C. D., Flow Electrolysis Cells for the Synthetic Organic Chemistry Laboratory. Chem. Rev. 2018, 118 (9), 4573-4591.

24. Wu, T.; Nguyen, B. H.; Daugherty, M. C.; Moeller, K. D., Paired Electrochemical Reactions and the On-Site Generation of a Chemical Reagent. Angew. Chem. Int. Ed. 2019, 58 (11), 3562-3565.

25. (a) Kockmann, N.; Thenée, P.; Fleischer-Trebes, C.; Laudadio, G.; Noël, T., Safety assessment in development and operation of modular continuous-flow processes. React. Chem. Eng.
2017, 2 (3), 258-280; (b) Gutmann, B.; Cantillo, D.; Kappe, C. O., Continuous-Flow Technology - A Tool for the Safe Manufacturing of Active Pharmaceutical Ingredients. Angew. Chem. Int. Ed. 2015, 54 (23), 6688-6728.

26. (a) Imada, Y.; Okada, Y.; Noguchi, K.; Chiba, K., Selective Functionalization of Styrenes with Oxygen Using Different Electrode Materials: Olefin Cleavage and Synthesis of Tetrahydrofuran Derivatives. Angew. Chem. Int. Ed. 2019, 58 (1), 125-129; (b) Wu, X.; Davis, A. P.; Fry, A. J., Electrocatalytic Oxidative Cleavage of Electron-Deficient Substituted Stilbenes in Acetonitrile-Water Employing a New High Oxidation Potential Electrocatalyst. An Electrochemical Equivalent of Ozonolysis. Org. Lett. 2007, 9 (26), $5633-5636$

27. (a) Schweitzer-Chaput, B.; Horwitz, M. A.; de Pedro Beato, E.; Melchiorre, P., Photochemical generation of radicals from alkyl electrophiles using a nucleophilic organic catalyst. Nat. Chem. 2019, 11 (2), 129-135; (b) Aschmann, S. M.; Arey, J.; Atkinson, R., Formation of p-cymene from $\mathrm{OH}+\gamma$-terpinene: $\mathrm{H}$-atom abstraction from the cyclohexadiene ring structure. Atmos. Environ. 2011, 45 (26), 4408-4411.

28. Sandford, C.; Edwards, M. A.; Klunder, K. J.; Hickey, D. P.; Li, M.; Barman, K.; Sigman, M. S.; White, H. S.; Minteer, S. D., A synthetic chemist's guide to electroanalytical tools for studying reaction mechanisms. Chemical Science 2019, 10 (26), 6404-6422.

\section{TOC graphic}

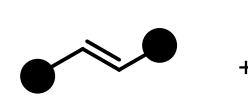

Alkene

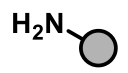

Amine

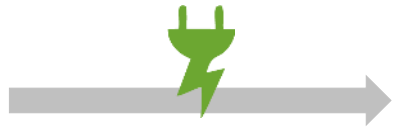

Electrochemical

Anodic Oxidation

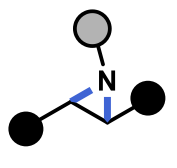

Aziridine

commodity chemicals - broad scope - 5 min reaction time - scalable 